\title{
Reliability of Small Molecule Organic Photovoltaics with Electron-Filtering Compound Buffer Layers
}

\author{
Quinn Burlingame, Byeongseop Song, Laura Ciammaruchi, Gloria Zanotti, \\ Jeanne Hankett, Zhan Chen, Eugene A. Katz, and Stephen R. Forrest*
}

Electron-filtering compound buffer layers (EF-CBLs) improve charge extraction in organic photovoltaic cells (OPVs) by blending an electronconducting fullerene with a wide energy gap exciton-blocking molecule. It is found that devices with EF-CBLs with high glass transition temperatures and a low crystallization rate produce highly stable morphologies and devices. The most stable OPVs employ $1: 1$ 2,2',2"-(1,3,5-benzenetriyl tris-[1-phenyl$1 \mathrm{H}$-benzimidazole] TPBi: $\mathrm{C}_{70}$ buffers that lose $<20 \%$ of their initial power conversion efficiency of $6.6 \pm 0.6 \%$ after $2700 \mathrm{~h}$ under continuous simulated AM1.5C illumination, and show no significant degradation after 100 days of outdoor aging. When exposed to 100 -sun $\left(100 \mathrm{~kW} \mathrm{~m}^{-2}\right)$ concentrated solar illumination for $5 \mathrm{~h}$, their power conversion efficiencies decrease by $<8 \%$. Moreover, it is found that the reliability of the devices employing stable EF-CBLs has either reduced or no dependence on operating temperature up to $130^{\circ} \mathrm{C}$ compared with BPhen: $\mathrm{C}_{60}$ devices whose fill factors show thermally activated degradation. The robustness of TPBi: $\mathrm{C}_{70}$ devices under extreme aging conditions including outdoor exposure, high temperature, and concentrated illumination is promising for the future of OPV as a stable solar cell technology.

\section{Introduction}

Advances in materials, deposition technologies, and device architectures continue to drive improvements in the power conversion efficiencies (PCE) of organic photovoltaic (OPV) cells. ${ }^{[1-4]}$ Due to the large variety of materials and structures explored, a general understanding of the factors leading to high reliability is needed to make a significant impact on their successful, widespread deployment. ${ }^{[5-7]}$ One important component influencing the lifetime of OPVs is the buffer layer located between the cathode and the photoactive layer. Buffer layers are used to confine excitons within the charge generation region, tune the optical field intensity within the active region, protect the active layer from damage during metal cathode deposition, ${ }^{[8]}$ and transport charge to the appropriate electrode..$^{[9,10]}$ Recently, a class of electron-filtering compound buffer layers (EF-CBLs) has been introduced that simultaneously achieve high conductivity and efficient exciton blocking by blending a wide energy gap and electrically insulating exciton blocking molecule with a conductive fullerene. ${ }^{[3,8]}$ These improvements result in high fill factors (FF) and PCE even at light intensities exceeding one sun $\left(1 \mathrm{~kW} \mathrm{~m}^{-2}\right) \cdot{ }^{[8]}$ The impact of such buffers on device operational lifetime has shown promise, ${ }^{[11]}$ but has yet to be explored in conjunction with stable, blended active-layer OPVs.

Accelerated aging can provide valuable insights into the processes underlying device degradation. ${ }^{[12-15]}$ The longest-lived OPV cells now take more than a year to degrade to $80 \%$ of their initial PCE under one sun illumination, making conventional lifetime testing increasingly impractical. ${ }^{[16-18]}$ In complex OPVs, optimization must occur across a large device architectural and materials space, thereby highlighting the importance of developing accurate methodologies for accelerating and understanding degradation. Exposure to elevated temperature,
Q. Burlingame, B. Song, Prof. S. R. Forrest

Department of Electrical Engineering and Computer Science

University of Michigan

Ann Arbor, MI 48109, USA

E-mail: stevefor@umich.edu

L. Ciammaruchi, ${ }^{[+]}$G. Zanotti, ${ }^{[+]}$Prof. E. A. Katz

Department of Solar Energy and Environmental Physics

Jacob Blaustein Institutes for Desert Research

Ben-Gurion University of the Negev

Sede Boqer Campus, 84990, Israel

J. Hankett, Prof. Z. Chen

Department of Chemistry

University of Michigan

Ann Arbor, MI 48109, USA
Prof. E. A. Katz

Ilse Katz Institute of Nano-Science and Technology

Ben-Gurion University of the Negev

Be'er Sheva 84105, Israel

Prof. S. R. Forrest

Department of Materials Science and Engineering

University of Michigan

Ann Arbor, MI 48109, USA

Prof. S. R. Forrest

Department of Physics

University of Michigan

Ann Arbor, MI 48109, USA

[+]Present address: ICFO - Institut de Ciències Fotòniques, Parc Mediterani de la Technologia, 08860 Castelldefels (Barcelona), Spain

${ }^{[++]}$Present address: CNR - Istituto di Struttura della Materia Via Salaria km 29,500, 00015, Monterotondo Scalo (Rm), Italy

DOI: 10.1002/aenm.201601094 
concentrated sunlight, continuous illumination, thermal or light cycling, and exposure to reactive atmospheres have been employed as potential acceleration techniques. ${ }^{[14,19-21]}$ An effective method should only speed up one of perhaps several mechanisms responsible for degradation, and should not promote new failure modes that are different than those experienced by the device under normal operating conditions.

Thermally accelerated aging methods assume that the degradation of a parameter, $p$, proceeds at a thermally activated rate, $k_{\text {deg }}(T)$

$$
k_{\mathrm{deg}}(T)=A \exp \left(\frac{-E_{\mathrm{A}}}{k_{\mathrm{B}} T}\right)
$$

where $A$ is a constant, $E_{\mathrm{A}}$ is the activation energy leading to degradation, $k_{\mathrm{B}}$ is Boltzmann's constant, and $T$ is the temperature. The rate at each temperature is found by fitting the value of $p$ over time, $t$, to

$$
p(t)=\alpha \exp \left(-k_{\mathrm{deg}}(T) t\right)+\beta
$$

where $\alpha$ and $\beta$ are constants. If more than one mechanism is active, a multiexponential fit similar to Equation (2) can be used to extract additional failure rates.

Here, we explore the impact of using various EF-CBLs on the stability of archetype tetraphenyldibenzoperiflanthene (DBP): $\mathrm{C}_{70}$ planar-mixed heterojunction OPV cells at elevated temperatures and high intensity illumination to accelerate and identify the most active performance failure mechanisms. ${ }^{[22]}$ X-ray diffraction (XRD), Fourier transform infrared (FTIR) spectroscopy, and differential scanning calorimetry (DSC) measurements are used to evaluate the changes induced in exciton blocking compounds employed in efficient EF-CBLs. We find that devices with EF-CBLs have longer operational lifetimes than those with a neat bathophenanthroline (BPhen) buffer, which is attributed to the improved morphological stability of the blends. While all devices have relatively stable open-circuit voltages $\left(V_{\mathrm{OC}}\right)$ and exhibit a linear decrease in short-circuit current density $\left(U_{S C}\right)$ under continuous illumination, changes in $\mathrm{FF}$ are functions of EF-CBL composition and morphological stability.

We find that DBP: $\mathrm{C}_{70}$-based OPVs with BPhen: $\mathrm{C}_{60}$ EF-CBLs are the least stable among those studied. These buffer layers experience a thermally activated FF degradation due to morphological changes in BPhen with $T_{\mathrm{G}}=61{ }^{\circ} \mathrm{C}$. In contrast, devices employing 2,2',2"-(1,3,5-benzenetriyl tris-[1-phenyl$1 H$-benzimidazole] (TPBi, $\left.T_{\mathrm{G}}=120{ }^{\circ} \mathrm{C}\right): \mathrm{C}_{70}$ EF-CBLs have stable FFs with little evidence of degradation at temperatures up to $130{ }^{\circ} \mathrm{C}$. Finally, we study the performance of devices employing TPBi: $\mathrm{C}_{70}$ EF-CBLs both outdoors and under concentrated sunlight. Following a $5 \mathrm{~h}$ dose of 100 -sun $\left(100 \mathrm{~kW} \mathrm{~m}^{-2}\right)$ illumination, the active layer shows no changes in absorption while losing just 7\% in PCE and 2\% in external quantum efficiency (EQE). Finally, after $>100 \mathrm{~d}$ of outdoor operation, no degradation was apparent, suggesting that continuous illumination aging may underestimate OPV lifetime under real-world conditions.

This paper is organized as follows: In Section 2 we report experimental results. In Section 3, we discuss the theory of small molecule crystal growth and relate the thermal properties of various EF-CBLs to their morphological and OPV stability. Analysis of degraded devices following accelerated aging is also discussed in Section 3, and compared with state-of-the-art OPV devices from the literature based on the total energy generated before failure. Conclusions are presented in Section 4. In Section 5 we outline methods used to fabricate and test EF-EBLs and devices.

\section{Results}

X-ray diffraction measurements of $200 \mathrm{~nm}$ thick films of 1:1 exciton blocker:fullerene $\left(\mathrm{C}_{60}\right.$ or $\left.\mathrm{C}_{70}\right)$ on sapphire were taken both before and after aging for one week under simulated one sun AM1.5G illumination. After aging, a diffraction peak in the $1: 1 \mathrm{BPhen}: \mathrm{C}_{60}$ film appears at an angle, $2 \theta=13.7^{\circ}$ (Figure 1a), which is also observed in BPhen powder XRD patterns. The background intensity at $2 \theta<10^{\circ}$ of the tris[2,4,6trimethyl-3-(pyridine-3-yl)phenyl]borane (3TPYMB): $\mathrm{C}_{60}$ film (Figure $1 \mathrm{~b}$ ) decreased to reveal a broad feature extending from $2 \theta=9^{\circ}$ to $12^{\circ}$. The $1: 1 \mathrm{TPBi}: \mathrm{C}_{70}$ spectrum was featureless both before and after aging, as were the $3,3^{\prime}, 5,5^{\prime}$-tetra[(m-pyridyl)phen-3-yl]biphenyl (BP4mPy): $\mathrm{C}_{60}$ and $\mathrm{TPBi}^{\mathrm{C}} \mathrm{C}_{60}$ spectra (not shown).

The glass transition temperature $\left(T_{\mathrm{G}}\right)$ of the wide energy gap exciton blockers BPhen, BP4mPy, 3TPYMB, and TPBi obtained by DSC are $61,105,106$, and $120^{\circ} \mathrm{C}$, respectively, and are listed in Table 1. Liquid-solid transitions were observed in BPhen and TPBi at 218 and $274{ }^{\circ} \mathrm{C}$, while BP4mPy and 3TPYMB did not melt under atmospheric pressure. From the DSC melting peaks, we calculate an enthalpy of fusion of $79.9 \mathrm{~kJ} \mathrm{~mol}^{-1}$ for BPhen, and $46.6 \mathrm{~kJ} \mathrm{~mol}^{-1}$ for TPBi, indicating that BPhen has a larger intermolecular cohesive binding energy. ${ }^{[23]}$ The vaporization temperatures in vacuum $\left(1 \times 10^{-6}\right.$ Torr $)$ of the materials follow a similar trend, where TPBi evaporates at $320{ }^{\circ} \mathrm{C}$, BP4mPy at $350{ }^{\circ} \mathrm{C}, 3 \mathrm{TPYMB}$ at $240{ }^{\circ} \mathrm{C}$, and BPhen at $230{ }^{\circ} \mathrm{C}$.

Figure 2 shows the FTIR absorption spectra for $\mathrm{C}_{60}, \mathrm{C}_{70}$, DBP, 3TPYMB, BP4mPy, TPBi, and BPhen both before (asgrown) and after aging for 1 week under one sun, AM1.5G simulated solar illumination in $\mathrm{N}_{2}$. No changes are observed in the $\mathrm{C}_{70}$, DBP, 3TPYMB, BP4mPy, or TPBi spectra. In contrast, peaks at wavenumbers of 1612, 1382, 921, 842, and $809 \mathrm{~cm}^{-1}$ become more pronounced in the BPhen spectrum, while the changes in $\mathrm{C}_{60}$ are consistent with photo-oligomerization. ${ }^{24,25]}$ The $\mathrm{CO}_{2}$ absorption band from $640-700 \mathrm{~cm}^{-1}$ is omitted for clarity.

The device structures used in lifetime tests are shown in the inset of Figure 3a. The performance of as-grown devices at $t=0$ with the five EF-CBLs are listed in Table 1 . The normalized $J_{\text {SC, }}$ $\mathrm{FF}, V_{\mathrm{OC}}$, and PCE under simulated AM 1.5G illumination (at ambient temperature $50-60{ }^{\circ} \mathrm{C}$ ) are plotted in Figure 3 as functions of time for TP60, BPPy60, and 3T60 cells. Figure 4 and Figure 5 show the normalized $J_{\mathrm{SC}}, \mathrm{FF}, V_{\mathrm{OC}}$, and PCE for BP60 devices between 50 and $80{ }^{\circ} \mathrm{C}$, and for TP70 devices between 55 and $130^{\circ} \mathrm{C}$. A biexponential was used to fit the $\mathrm{FF}(t)$ of BP60 with two rates, $k_{\text {fast }}(T)$ and $k_{\text {slow }}(T)$, as shown in Figure $4 \mathrm{~b}$ (solid lines). All data are normalized to the point at which the equilibrium temperature is reached. 

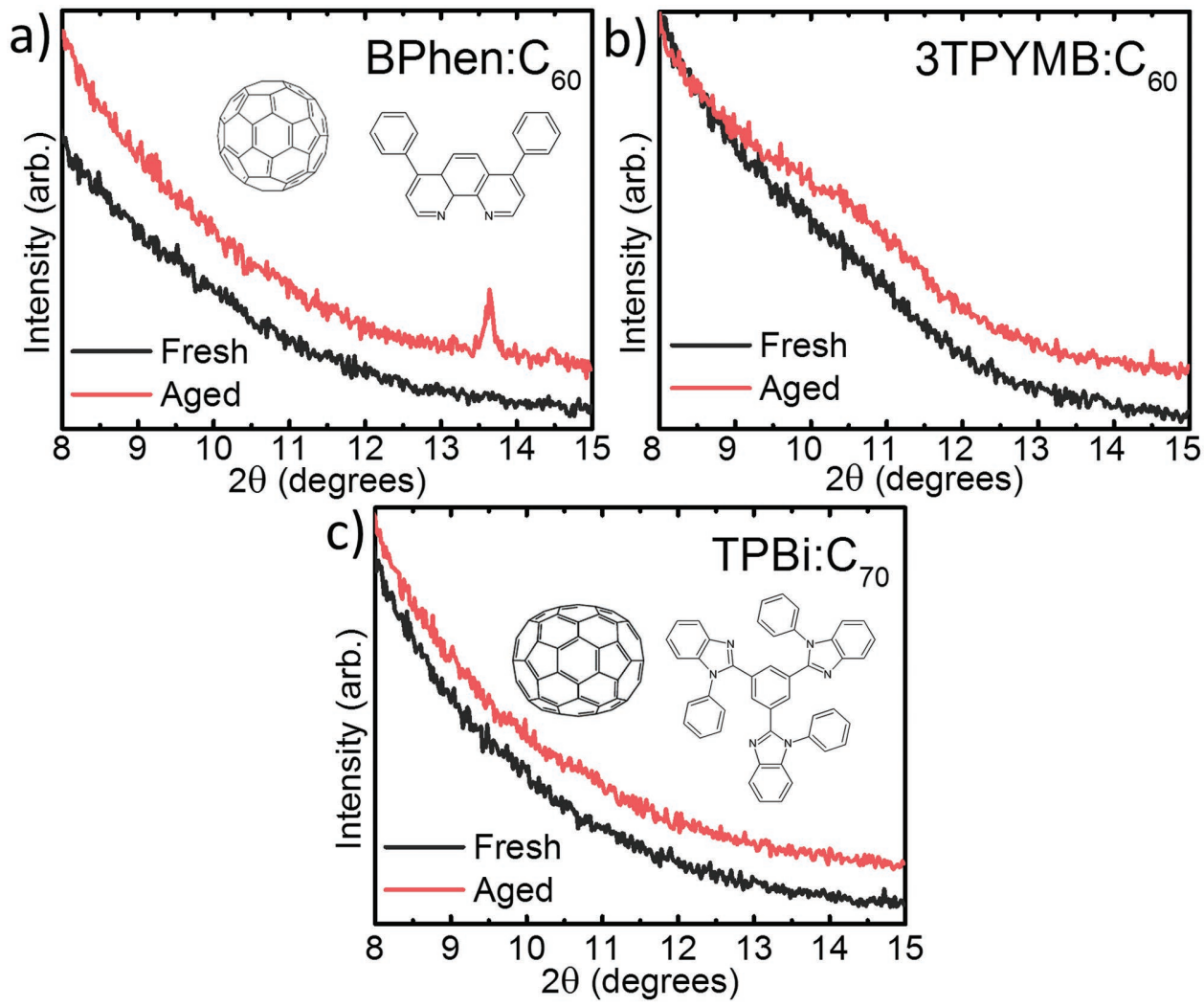

Figure 1. X-ray diffraction patterns of $200 \mathrm{~nm}$ thick films before (Fresh) and after aging (Aged) for one week under $1 \mathrm{~kW} \mathrm{~m} \mathrm{~m}^{-2}$ (one sun) illumination in $\mathrm{N}_{2}$ : a) $200 \mathrm{~nm}$ BPhen: $\mathrm{C}_{60}$ 1:1, b) 3TPYMB: $\mathrm{C}_{60}$ 1:1, c) TPBi: $\mathrm{C}_{70}$ 1:1. Molecular structural formulae are shown as insets: a) $\mathrm{C}_{60}$ (left) and BPhen (right), c) $\mathrm{C}_{70}$ (left) and TPBi (right). The spectra are offset along the $\gamma$-axis for clarity.

From Figure 3, Figure 4, and Figure 5, we observe that the $J_{\mathrm{SC}}$ of all devices decreases approximately linearly with time ( $5 \%$ to $10 \%$ per $1000 \mathrm{~h}$ ) under continuous, simulated AM $1.5 \mathrm{G}$ illumination. In contrast, $V_{\mathrm{OC}}$ is stable for BPPy60, TP60, and TP70. A decrease in $V_{\mathrm{OC}}$ is observed for $3 \mathrm{~T} 60$ cells (by $4 \%$ after $320 \mathrm{~h}$ ) and BP60 cells (by $9 \%$ at $80{ }^{\circ} \mathrm{C}$ and by $2 \%$ after $800 \mathrm{~h}$ at all other temperatures). A similar trend is observed for $\mathrm{FF}$ where TP70, TP60, and BPPy60 cells are stable, while BP60 loses $11 \%$ to $23 \%$ after $800 \mathrm{~h}$ depending on temperature, and 3 T60 decreases by $6 \%$ over $300 \mathrm{~h}$ of operation. The time for PCE to decrease by $20 \%$ from its starting value at ambient temperature (known as $\left.T_{80}\right)^{[14]}$ is $800 \mathrm{~h}$ for BP60, $2700 \mathrm{~h}$ for TP70,

Table 1. Principal photovoltaic parameters of organic photovoltaic cells comprising electron filtering-charge blocking layer (EF-CBL) with various glass transition temperatures $\left(T_{\mathrm{G}}\right)$.

\begin{tabular}{lcccccc}
\hline EF-CBL & $\begin{array}{c}\text { Blocker } T_{\mathrm{C}} \\
{\left[{ }^{\circ} \mathrm{C}\right]}\end{array}$ & $\begin{array}{c}J_{\mathrm{SC}} \\
{\left[\mathrm{mA} \mathrm{cm}^{-2}\right]}\end{array}$ & $\begin{array}{c}\mathrm{FF} \\
{[\%]}\end{array}$ & $\begin{array}{c}V_{\text {OC }} \\
{[\mathrm{V}]}\end{array}$ & $\begin{array}{c}\text { PCE } \\
{[\%]}\end{array}$ & $\begin{array}{c}T_{80} \\
{[\mathrm{~h}]}\end{array}$ \\
\hline BP60 & 61 & $12.1 \pm 1$ & $62 \pm 1$ & $0.93 \pm 0.01$ & $6.9 \pm 0.5$ & 800 \\
TP70 & 120 & $11.7 \pm 1$ & $61 \pm 1$ & $0.93 \pm 0.01$ & $6.6 \pm 0.6$ & 2700 \\
TP60 & 120 & $11.8 \pm 1$ & $62 \pm 1$ & $0.91 \pm 0.01$ & $6.7 \pm 0.5$ & $2200 * *$ \\
3T60 & 106 & $12.2 \pm 1$ & $59 \pm 1$ & $0.93 \pm 0.01$ & $6.7 \pm 0.5$ & $1100 *$ \\
BPPy60 & 105 & $11.8 \pm 1$ & $57 \pm 1$ & $0.91 \pm 0.01$ & $6.1 \pm 0.5$ & $1700 *$ \\
\hline
\end{tabular}

$* T_{80}$ extrapolated
$2200 \mathrm{~h}$ for TP60, $1100 \mathrm{~h}$ for 3T60, and $1700 \mathrm{~h}$ for BPPy60 (the last three lifetimes are extrapolated).

Dark $J-V$ characteristics were measured for all devices both before and after aging under continuous, simulated AM1.5G illumination. Results for BP60 and TP70 cells are shown in Figure 6. The dark current at $<0.8 \mathrm{~V}$ in the as-grown BP60 devices was considerably smaller than for the aged devices (Figure 6a). After $800 \mathrm{~h}$, devices aged at higher temperatures exhibit higher dark currents. To characterize losses due to the dark current increase, we separate the illuminated $J-V$ characteristics obtained under 1 sun into two parts: a shunt current that is linear with voltage $\left(U_{\mathrm{SH}}\right)$, and a nonlinear component due to recombination, $\left(J_{\mathrm{REC}}\right)$. We extract $J_{\mathrm{SH}}$ by linearly extrapolating the current near $0 \mathrm{~V}$, and $J_{\text {REC }}$ by taking the difference between the measured current and $J_{\mathrm{SH}}$ at the maximum power point. These components are plotted as functions of time and normalized to $J_{\mathrm{SC}}$ in Figure 7a,b. In contrast, the most stable devices (TP70) show almost no change after aging (Figure 6b), and exhibited no systematic dependence on temperature. The $J-V$ characteristics of the TP70 devices aged at intermediate temperatures are omitted for clarity.

The degradation rates, $k_{\text {fast }}(T)$ and $k_{\text {slow }}(T)$, extracted from the biexponential fits to $\mathrm{FF}(t)$ are plotted versus $1 / k_{\mathrm{B}} T$ at each aging temperature for BP60 (Figure 8). Using Equation (1), we find that the two activation energies are equal to within the error of the measurement: $0.56 \pm 0.06 \mathrm{eV}$ for $k_{\text {fast }}(T)$ and $0.53 \pm 0.13 \mathrm{eV}$ for $k_{\text {slow }}(T)$. 


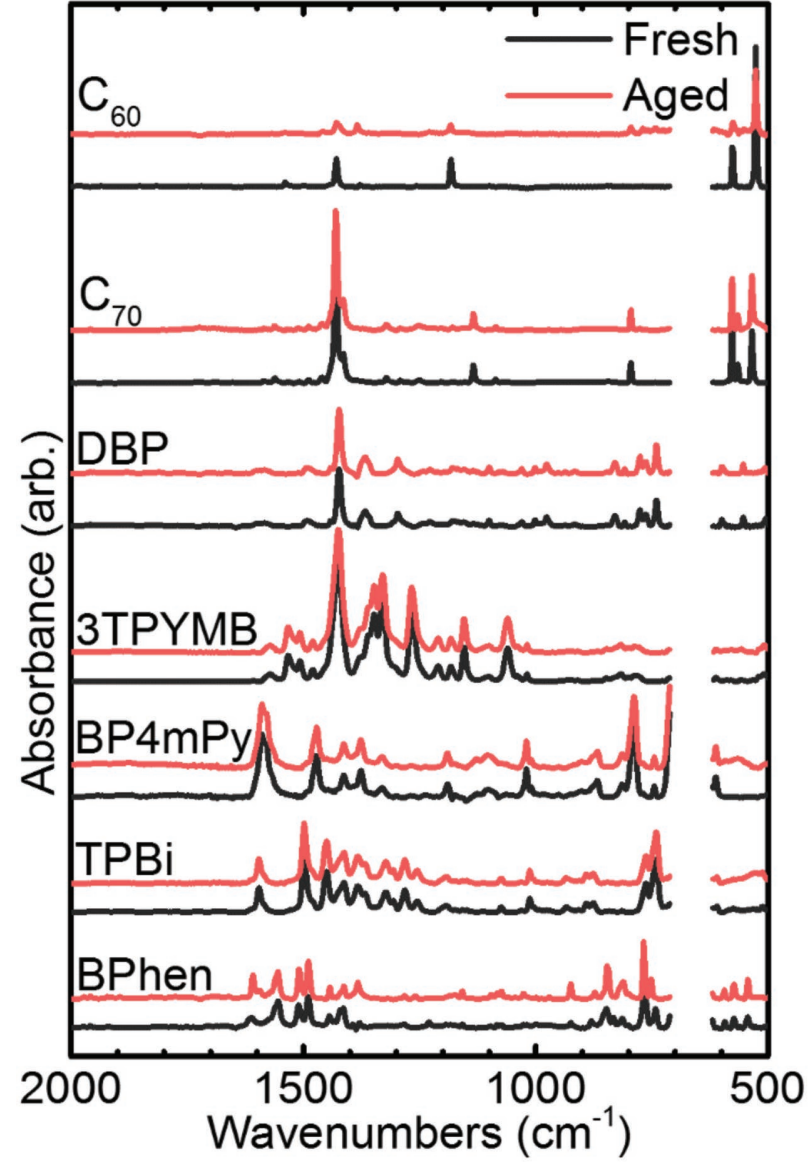

Figure 2. Fourier transform infrared absorbance spectra of $100 \mathrm{~nm}$ thick films of $\mathrm{C}_{60}, \mathrm{C}_{70}$, DBP, 3TPYMB, BP4mPy, TPBi, and BPhen films on $\mathrm{KBr}$ before (Fresh) and after aging (Aged) for one week under simulated $1 \mathrm{~kW} \mathrm{~m}{ }^{-2}$ (one sun) AM1.5C illumination in $\mathrm{N}_{2}$.

To understand the performance of OPVs in an actual operating environment, four identical TP70 devices were placed outdoors from November 8th, 2015 to February 21st, 2016. The normalized responsivity (which equals the ratio of $J_{\mathrm{SC}}$ to the solar irradiance), FF, $V_{\mathrm{OC}}$, and PCE as functions of time are plotted in Figure 9. Prior to catastrophic package failure resulting from a leak in the epoxy seal at day 104, no discernable degradation was observed. After package failure, the $J_{\mathrm{SC}}$ and responsivity degraded rapidly due to oxidation and water ingress, highlighting the importance of robust encapsulation.

Since the degradation rates of some devices were not increased by thermal stress, we exposed the most stable TP70 devices and a $54 \mathrm{~nm}$ thick 1:8 DBP: $\mathrm{C}_{70}$ thin film to 100 -sun concentrated sunlight $\left(100 \mathrm{~kW} \mathrm{~m}^{-2}\right)$ for $5 \mathrm{~h}$. Figure 10a shows the $J-V$ characteristics under one sun illumination both before and after aging. The $V_{\mathrm{OC}}$ is stable, while a decrease of $2 \%$ in $J_{\mathrm{SC}}$ and $5 \%$ in $\mathrm{FF}$ are observed. No change in the optical absorbance of the $\mathrm{DBP}: \mathrm{C}_{70}$ active layer blend was observed after high intensity exposure (left axis of Figure 10b). The integrated photocurrent calculated from the EQE (right axis of Figure 10b) decreases by $2 \%$, which is comparable in magnitude to the decrease in $J_{\mathrm{SC}}$ measured at one sun.

\section{Discussion}

Blending organic materials can result in a morphology that is more stable than either of the constituents comprising the mixture. ${ }^{[26,27]}$ The compounds act to stabilize each other by breaking up the interactions between similar molecules, which prevents the formation of aggregates and growth of crystallites. Here, we find that $T_{\mathrm{G}}$ of the blocking molecule in the EF-CBL can be predictive of morphological and device stability. Nevertheless, we caution that molecular diffusion and crystallite domain growth can still occur at $T<T_{\mathrm{G}} \cdot{ }^{[28]}$ Materials with a low enthalpy of fusion, high $T_{\mathrm{G}}$ and high melting point produce lower crystallization rates, leading to more stable amorphous states that are required for reliable OPVs. ${ }^{[28,29]}$

In Figure 1a we find that including $\mathrm{C}_{60}$ in the EF-CBL mixture significantly impedes, but does not completely eliminate BPhen crystallization, an effect that can induce interfacial charge build up and low resistance shunts through organic heterojunctions $(\mathrm{HJs}){ }^{[26,30,31]}$ The improved lifetime of blended cathode buffers was also shown for the bathocuproine: $\mathrm{C}_{60}$ system in planar OPVs. ${ }^{[11]}$ As a result of the stabilized morphology, the lifetime of the BP60 EF-CBL devices $\left(T_{80}=800 \mathrm{~h}\right)$ under continuous one sun simulated illumination is two orders of magnitude longer than devices with neat BPhen buffers reported by Song et al. ${ }^{[30]}$ TPBi has a significantly higher $T_{\mathrm{G}}=$ $120^{\circ} \mathrm{C}$, melting point of $274^{\circ} \mathrm{C}$, and lower enthalpy of fusion of $46.46 \mathrm{~kJ} \mathrm{~mol}^{-1}$ than BPhen; thus the XRD spectra of aged TPBi blends with either $\mathrm{C}_{60}$ or $\mathrm{C}_{70}$ (Figure 1c) show no evidence of morphological changes. The $T_{\mathrm{G}}$ 's of 3 TPYMB and BP4mPy are 105 and $106{ }^{\circ} \mathrm{C}$, respectively, but neither material melted at temperatures up to $400{ }^{\circ} \mathrm{C}$, and their XRD patterns did not show evidence of crystallization. Their large size compared to BPhen and increased degrees of intramolecular rotational freedom likely limits their tendency to form crystalline domains. ${ }^{[32]}$ No change was observed in the BP4mPy: $\mathrm{C}_{60}$ XRD spectra after aging, although a broad amorphous feature appeared in the 3TPYMB: $\mathrm{C}_{60}$ spectra, suggesting that the morphology changed over time. The detailed nanomorphology (i.e., packing density, cluster size, and molecular orientation) within the EF-CBL blends was not revealed in the XRD spectra, although such information may be accessible with the use of more specialized characterization techniques that are beyond the scope of this work. ${ }^{[33]}$

The trends in FF and $V_{\mathrm{OC}}$ follow those observed in XRD, where TP70 (Figure 5), TP60 (Figure 3a), and BPPy60 (Figure $3 \mathrm{~b}$ ) are stable under continuous illumination, while BP60 (Figure 4) and 3T60 (Figure 3c) show decreases in these operating parameters. The $J_{\mathrm{SC}}$ of all devices decreases approximately linearly under continuous illumination, and has a comparatively weak dependence on EF-CBL composition or aging temperature. The origin of the decrease in $J_{\mathrm{SC}}$ was not apparent from the thin film analysis methods employed here. However, the optically generated polaron density in neat films is low compared with the density in the illuminated device since the films lack a junction to dissociate excitons. Therefore, polaron-induced degradation such as exciton annihilation may be underrepresented in the thin film analyses such as in the FTIR spectra. 


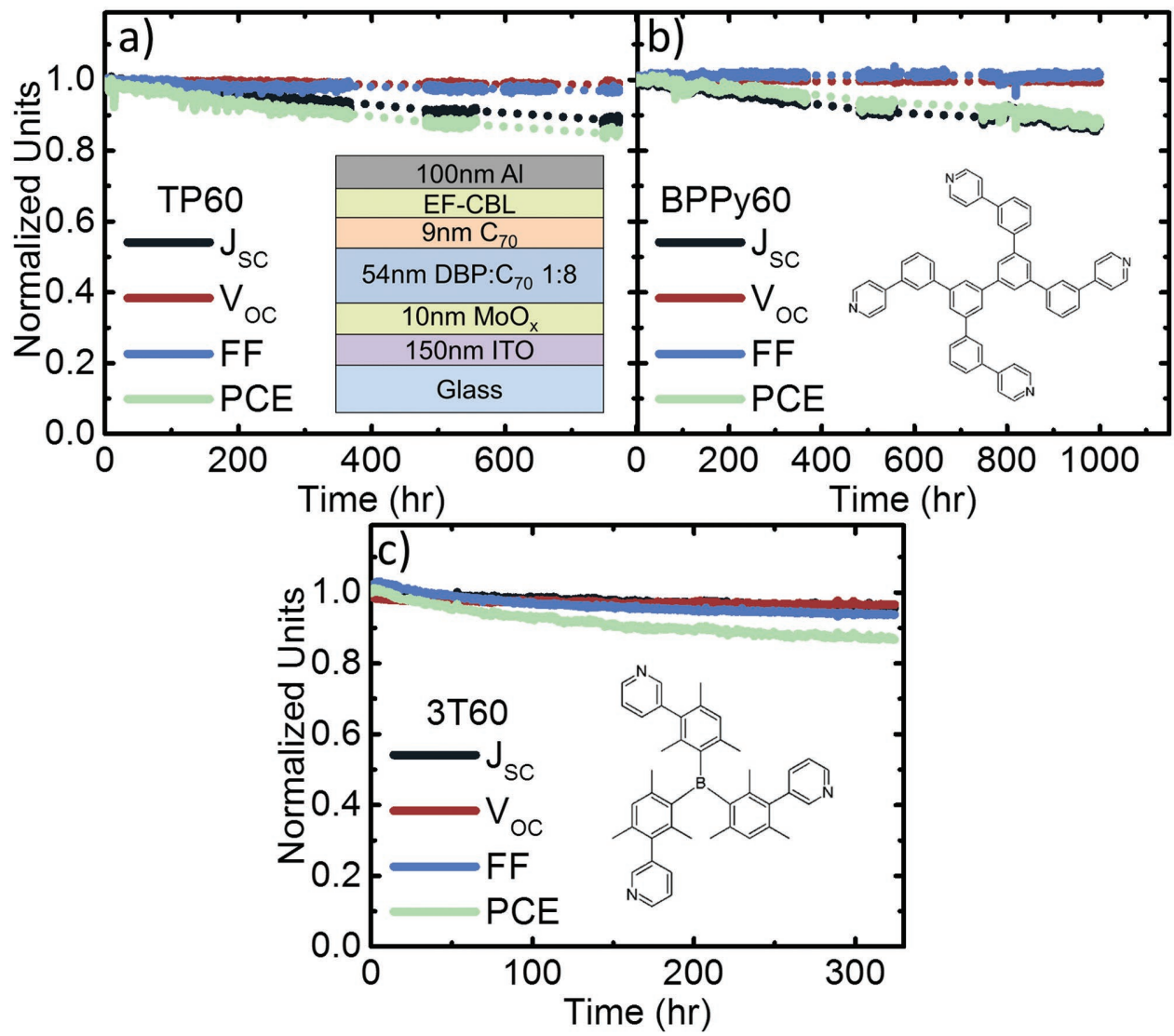

Figure 3. Normalized short circuit current $U_{S C}$ ), fill factor (FF), open circuit voltage $\left(V_{O C}\right)$, and power conversion efficiency (PCE) versus time under continuous simulated AM 1.5G illumination for a) TP60, b) BPPy60, and c) 3T60 OPV cells, with the device structure shown in the inset of (a). Molecular structural formulae for BP4mPy and 3TPYMB are shown in the insets of (b) and (c), respectively.

The FTIR spectra in Figure 2 suggest that $\mathrm{C}_{70}$, DBP, 3TPYMB, BP4mPy, and TPBi are photochemically stable under illumination in a nonreactive gas atmosphere. The largest changes are observed in $\mathrm{C}_{60}$ that oligomerizes under illumination, which has been shown to result in a decrease in the exciton diffusion length and broadened optical absorption. ${ }^{[25]}$ Here, $\mathrm{C}_{60}$ is used as an electron conductor in some EF-CBLs, and its effect on lifetime compared with $\mathrm{C}_{70}$ is a likely the result of increased absorption in the EF-CBL. The discrepancy in $J_{\mathrm{SC}}$ degradation rate between the various $\mathrm{C}_{60}$ EF-CBLs may be due to small changes in charge extraction as the morphologies of the buffers change with aging; an effect that should be largest for buffers with the lowest $T_{\mathrm{G}}$. The relative changes in BPhen peak height are due to crystallization.

As noted, the EF-CBL influences charge extraction and exciton recombination, and hence its composition impacts the PCE. ${ }^{[3,8]}$ Previously, Xiao et al. demonstrated that the PCEs of devices with a BPhen: $\mathrm{C}_{60} / \mathrm{BPhen}$ EF-CBL are $>25 \%$ higher than those with a neat BPhen exciton blocking buffer, primarily resulting from increases in $\mathrm{FF} \cdot{ }^{[8]}$ Excitons at the acceptor-buffer interface are efficiently blocked due to a large difference in both the lowest unoccupied molecular orbital (LUMO) and highest occupied MO (HOMO) energies between BPhen and the fullerenes, while the high conductivity and the alignment of the $\mathrm{C}_{60}$ EF-CBL and the $\mathrm{C}_{70}$ acceptor orbital energies leads to efficient electron extraction. The energy gaps of TPBi, BP4mPy, and 3TPYMB are sufficiently large to block excitons and have stable morphologies compared with BPhen, leading to more stable OPV operation (Table 1).

After aging the BP60 devices, we observe a temperature dependent increase in dark current (Figure 6a). Accordingly, the dark current subtracts from the photocurrent, shifting the maximum power point toward the origin, thus reducing both FF and PCE. ${ }^{[23]}$ From the biexponential fits to FF(t), two degradation rates are extracted, $k_{\text {fast }}(T)$ and $k_{\text {slow }}(T)$. We find that $J_{\mathrm{SH}} / J_{\mathrm{SC}}$ can be fit at each temperature by a single exponential (Equation (2)) with the rate $k_{\text {slow }}(T)$ from the fit to $F F(t)$, shown in Figure $7 \mathrm{a}$. The effect of $J_{\mathrm{SH}}$ on $\mathrm{FF}$ is relatively small, accounting for only $1 \%$ to $3 \%$ of the loss, depending on temperature. Crystallization of BPhen has been shown to penetrate from the metal cathode into the device active region, ${ }^{[30]}$ and is likely responsible for $J_{\mathrm{SH}}$ in the devices studied here. In contrast, changes in $J_{\mathrm{REC}}$ result in a 7\% to $13 \%$ decrease of FF depending on aging temperature, as shown in Figure $7 \mathrm{~b}$. The solid line shows the result of a biexponential fit to $J_{\mathrm{REC}} / J_{\mathrm{SC}}$ using $k_{\text {slow }}(T)$ and $k_{\text {fast }}(T)$, where $\alpha<0$ in Equation (2). This asymmetric increase in forward-biased dark current is suggestive of an increase in recombination that may result from an increased defect density or decreased electron extraction efficiency at the buffer interface over time. ${ }^{[34,35]}$ The 

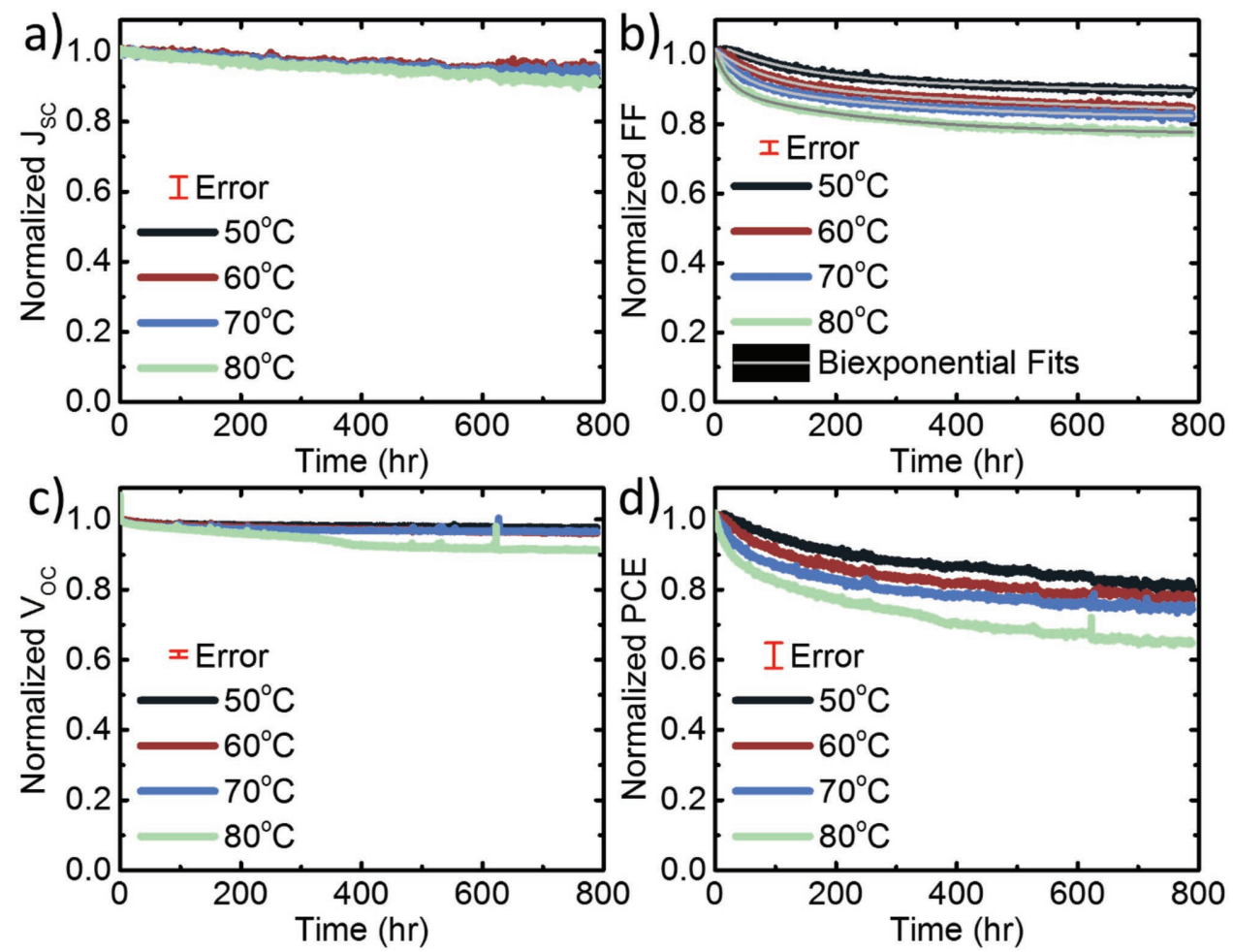

Figure 4. Normalized a) $J_{S C}$, b) FF with biexponential fits (dashed lines), c) $V_{O C}$, and d) PCE versus time at aging temperatures of 50, 60, 70, and $80^{\circ} \mathrm{C}$ for BP60 cells under continuous simulated AM1.5C illumination (one sun intensity).
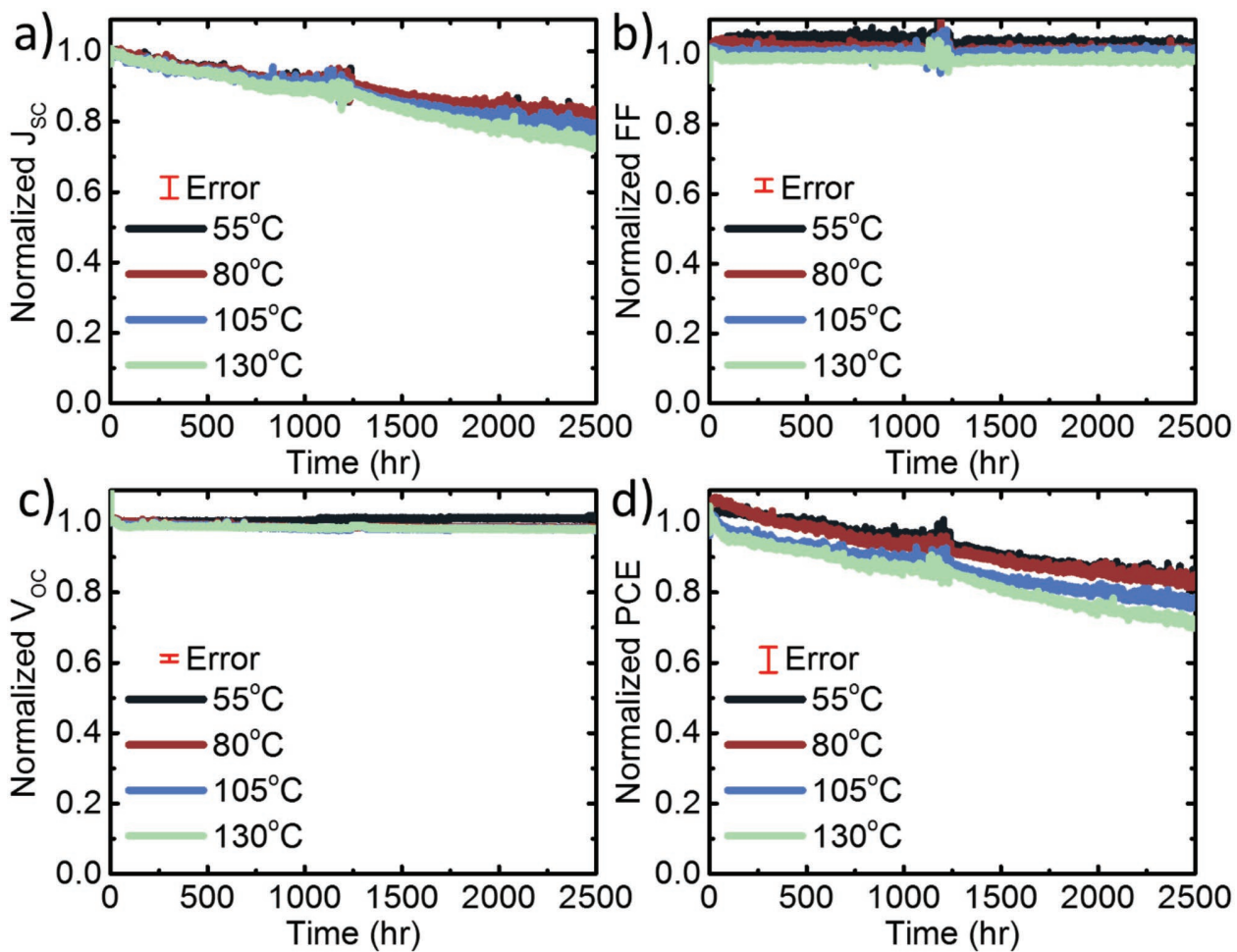

Figure 5. Normalized a) $\mathrm{JSC}_{\mathrm{SC}}$ b) FF, c) $V_{\mathrm{OC}}$, and d) PCE versus time at 55, 80, 105, and $130^{\circ} \mathrm{C}$ for TP70 cells under continuous simulated AM1.5C illumination (one sun intensity). The discontinuity in the data at $1200 \mathrm{~h}$ comes from replacement of the light source. 


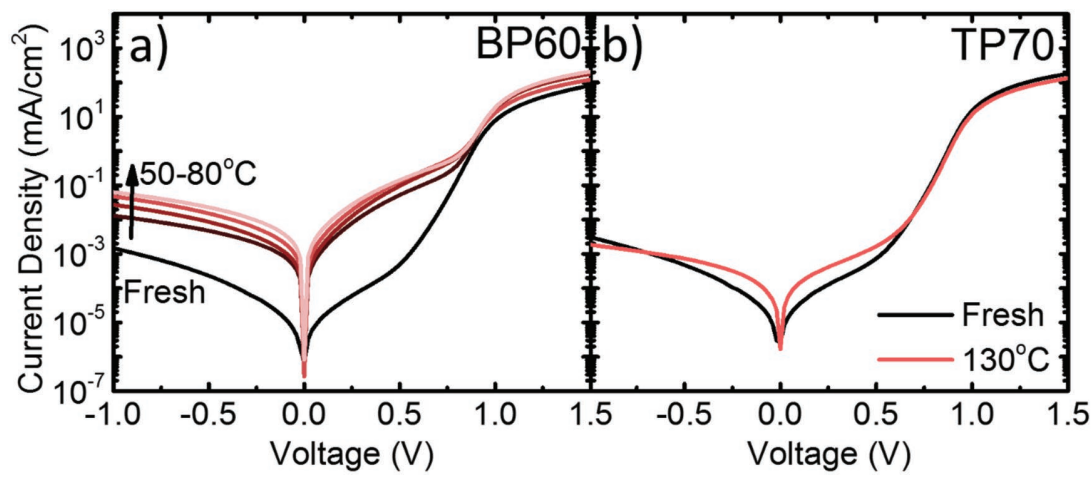

Figure 6. Dark current density versus voltage for a) BP60 devices before (Fresh) and after aging for $800 \mathrm{~h}$ at aging temperatures of $50,60,70$, and $80^{\circ} \mathrm{C}$ and b) TP70 before (Fresh) and after aging for $2700 \mathrm{~h}$ at $130^{\circ} \mathrm{C}$.
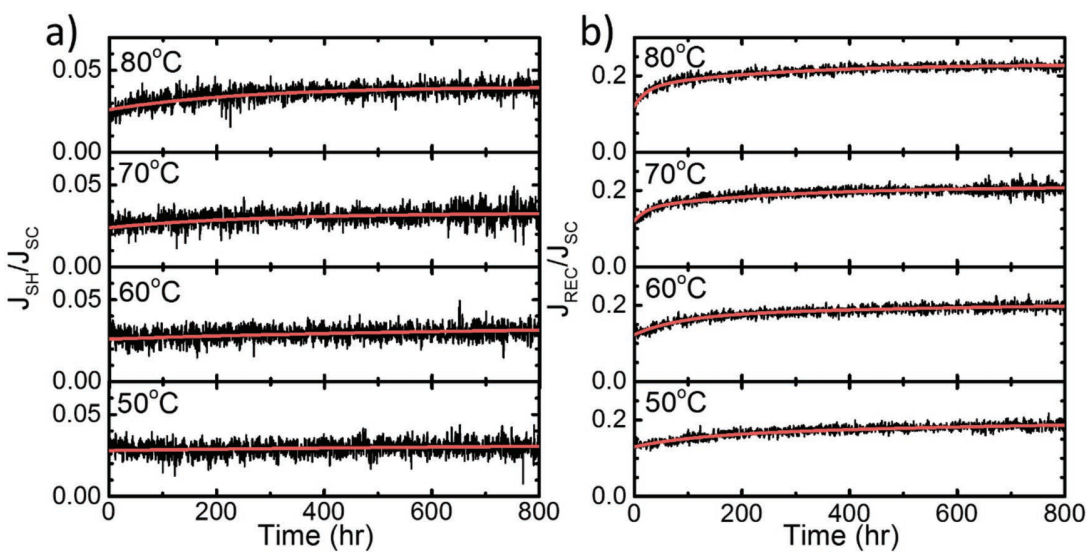

Figure 7. a) $J_{S H}$ and b) $J_{R E C}$ normalized to $J_{S C}$ as a function of time for BP60 devices aged at $50,60,70$, and $80^{\circ} \mathrm{C}$, with exponential or biexponential fits (lines) using the degradation rates extracted from $\mathrm{FF}(t)$.

remaining FF loss in BP60 that is not accounted for by the increased dark current $(5 \%$ to $9 \%$, depending on aging temperature) results from a reduction in voltage at the maximum power point. As seen in Figure 6b, the dark current of TP70 is stable compared with BP60, and consequently no change in FF is observed. Due to the relative stability of the EF-CBL devices that do not contain BPhen, both $J_{\mathrm{SH}}$ and $J_{\mathrm{REC}}$ likely result from the same process of BPhen crystallization. Thus, we expect that $E_{\mathrm{A}}$ of both $k_{\text {fast }}(T)$ and $k_{\text {slow }}(T)$ should be equal, and indeed this is the case to within experimental error, as shown in Figure 8.

The performance of a population of four TP70 devices aged under sunlight shows no degradation after $>100 \mathrm{~d}$ (see Figure 9). This is in contrast to the cells with the same TP70 device architecture but aged under continuous simulated illumination, which show a linear decrease in $J_{\mathrm{SC}}$ over time (Figure 5a). The results suggest that the lifetime of the devices under real-world operating conditions may be longer than they appear under simulated conditions. For example, the operational lifetime under real conditions consists of alternating illumination and dark exposure, and may therefore allow for recovery in the dark if the degradation is partially reversible. ${ }^{[21,36]}$ However, this conclusion remains to be proven by additional experiments since the outdoor exposure carried out under open circuit conditions is significantly less $(<500 \mathrm{~h}$ of one sun equivalent radiation) than the $2500 \mathrm{~h}$ maximum power operating point continuous illumination measurement using a solar simulator light source.

No change in absorption in the DBP: $\mathrm{C}_{70}$ active layer film was observed after illumination for $5 \mathrm{~h}$ under 100-sun intensity (Figure 10b left-axis). Under these conditions, the EQE of the TP70 device was slightly reduced between $\lambda=350$ and $600 \mathrm{~nm}$ (Figure $10 \mathrm{~b}$ right-axis). The $2 \%$ loss in $J_{\mathrm{SC}}$ obtained from integration of the EQE spectrum after aging is comparable to the $4 \pm 2 \%$ decrease in $J_{\mathrm{SC}}$ observed after a similar dose of photons under continuous simulated illumination $(500 \mathrm{~h})$. A $6 \%$ decrease in FF is also observed in Figure 10a, resulting from a significant increase in dark current that was not observed during continuous illumination (c.f. Figure 5b). Exciton-exciton or exciton-polaron annihilation may be responsible for the degradation, as their rates would be approximately four orders of magnitude higher at $100 \mathrm{~kW} \mathrm{~m}^{-2}$ than $1 \mathrm{~kW} \mathrm{~m}{ }^{-2} \cdot[37,38]$ Such processes are responsible for the degradation of blue phosphorescent organic light emitting diodes, but have not been similarly reported in OPVs.

In practical applications, solar cells must simultaneously achieve high efficiency and long-term reliability. It is useful, therefore, to define a figure of merit that is equal to the

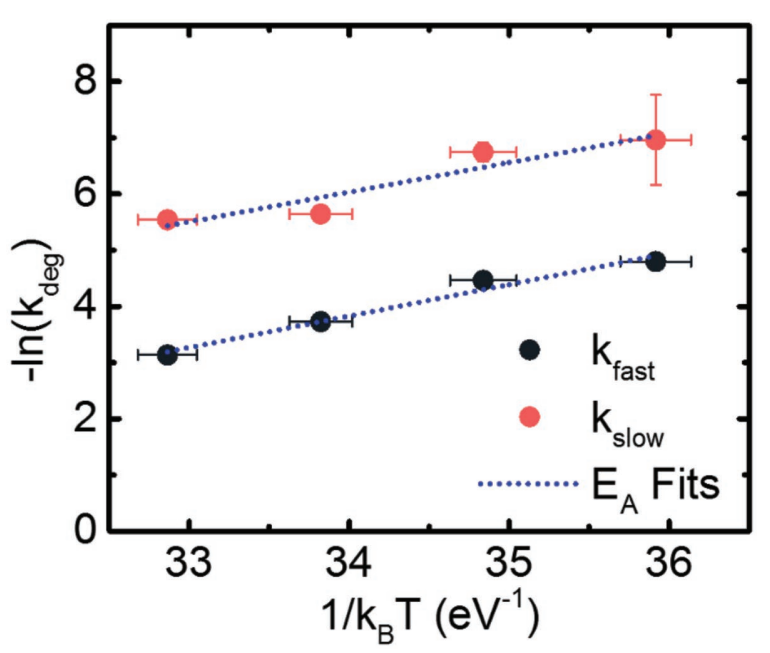

Figure 8. Natural logarithm of degradation rates $\left(k_{\text {fast }}\right.$ and $\left.k_{\text {slow }}\right)$ versus $1 / k_{\mathrm{B}} T$ obtained from biexponential fits to $\mathrm{FF}$ for $\mathrm{BP} 60$, where $T$ is the aging temperature. Linear fits used to extract the activation energy $\left(E_{A}\right)$ from each exponential are shown by the lines in the plot. 

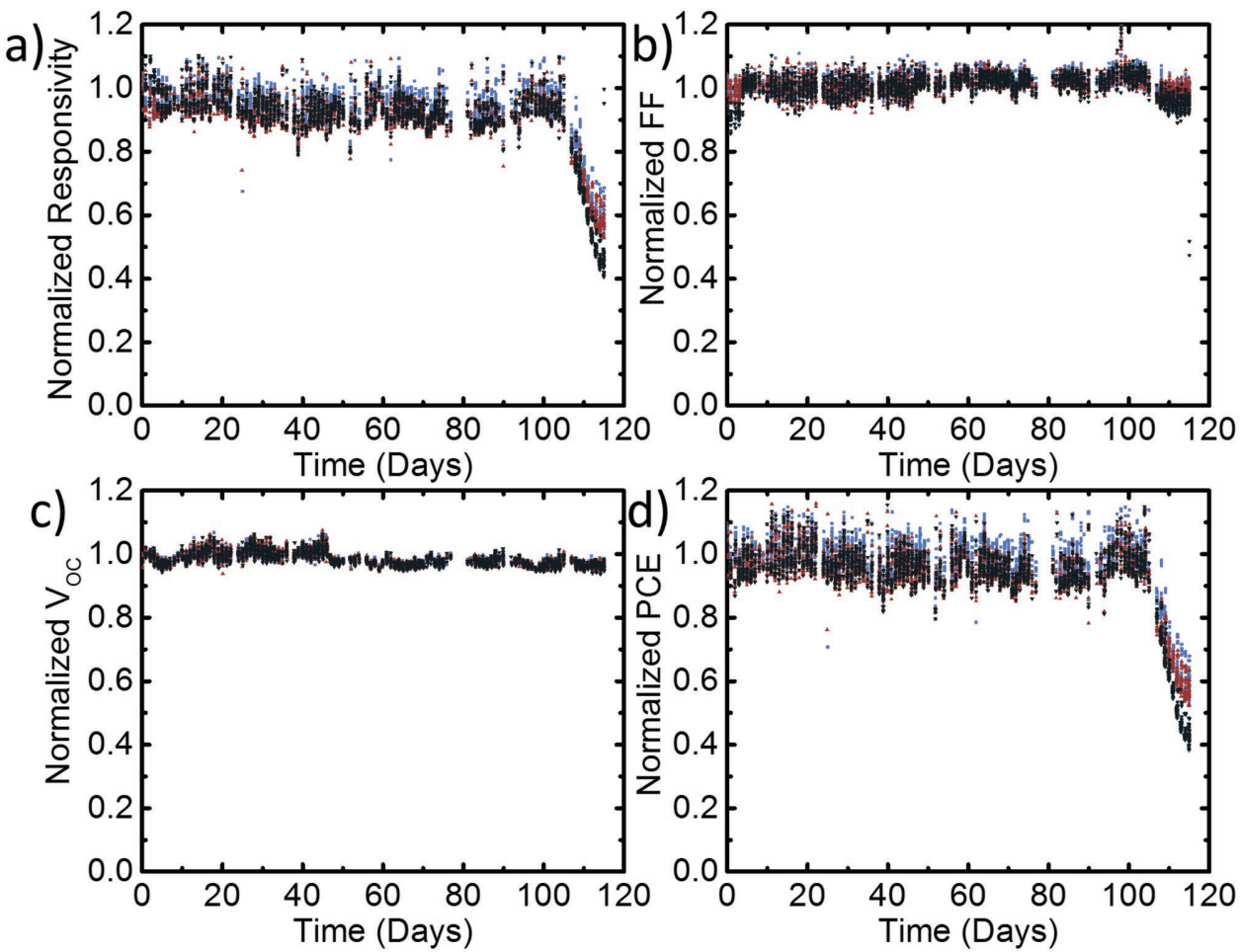

Figure 9. Normalized a) $J_{S C}$, b) FF, c) $V_{O C}$, and d) PCE versus time for four different TP70 cells aged outdoors. The sharp decrease in performance after $100 \mathrm{~d}$ is due to a failure of the epoxy-sealed package.

total energy generated by a device prior to falling below an acceptable level of performance. For this we assume that cell failure occurs at $T_{80}$. Then the total energy generated prior to failure is

$E_{80}=\int_{0}^{T_{80}} \operatorname{PCE}(t) \cdot P_{\text {inc }}(t) d t$

where $P_{\text {inc }}(t)$ is the solar irradiance as a function of time, $t$.

In Figure 11 we plot $E_{80}$ for the previously reported OPVs summarized in Table 2, including the TP70 devices studied here. ${ }^{[7,17,18,39-47]}$ Apparently, both lifetime and PCE have improved over the last several years, producing dramatic increases in $E_{80}$ from $<10^{6} \mathrm{~J} \mathrm{~m}^{-2}$ in 2005 to $5.9 \times 10^{8} \mathrm{~J} \mathrm{~m}^{-2}$ in this work. Some polymer and small molecule cells experience a significant decrease in initial efficiency (known as burn in), presumably due to morphological rearrangement following deposition, or chemical instabilities, although that is not observed in several cells investigated here. ${ }^{[14,16,18,45]}$ Among devices with $E_{80}>10^{8}$, only two have PCE > 5\%, and only three were aged using lamps with AM1.5G UV content. In all cases, the $E_{80}$ for organic solar cells still fall $>10$ times short of those attained by inorganic solar cells where $E_{80}>10^{10} \mathrm{~J} \mathrm{~m}^{-2}$ for $\mathrm{Si}, \mathrm{CdTe}$, and CuInGaSe 2 devices, with initial PCE $=13.4 \%$ to $20.5 \%$ and degradation rates $<1.2 \%$ per year. ${ }^{[48]}$
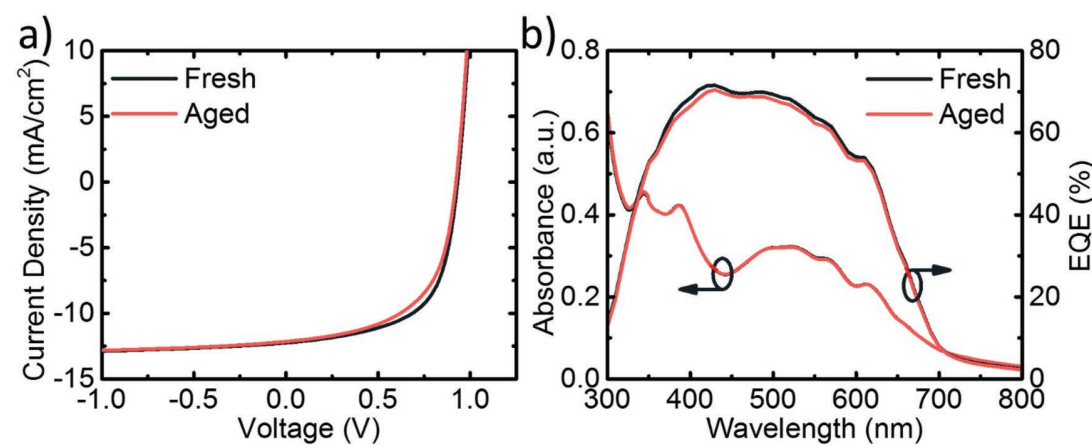

Figure 10. a) Current density versus voltage for TP70 cells before (Fresh) and after aging (Aged) under concentrated 100-sun illumination for $5 \mathrm{~h}$. b) Left axis: Optical absorbance versus wavelength for a $54 \mathrm{~nm}$ thick 1:8 DBP: $C_{70}$ film, and right axis: EQE of TP70 aged under the same conditions as (a).

\section{Conclusions}

The operational lifetimes of small-molecular-weight, planar-mixed HJ OPVs with different EF-CBLs were determined using a range of test conditions, and were related to their morphological and photochemical stabilities based on the analysis of XRD, FTIR, and DSC data. Compared to OPVs with neat BPhen cathode buffer layers; BP60, 3T60, TP60, TP70, and BPPy60 EF-CBLs were found be more morphological stable, leading to reduced degradation in their long-term performance characteristics. Exciton blocking molecules with a high $T_{G}$ and a reduced 


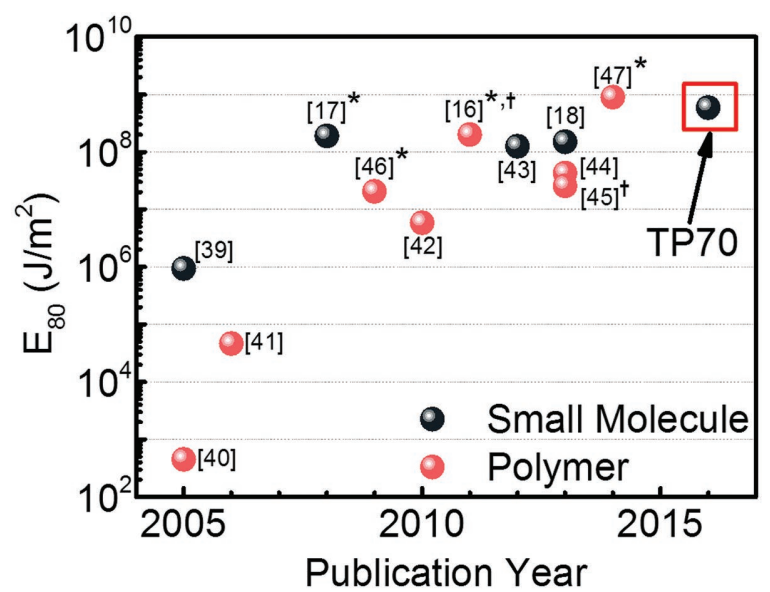

Figure 11. Energy produced prior to a loss of $20 \%$ in the power conversion efficiency $\left(E_{80}\right)$ versus publication year for the TP70 devices reported here, and previously reported OPV cells with literature references indicated. Device lifetime measured using light sources which include little or no UV light are noted with an asterisk (*). Some cells experience a "burn-in" for the first several hundred hours, during which $20 \%-40 \%$ of the initial PCE is lost, and are noted by a dagger ( $(\dagger)$. The $E_{80}$ calculated considers $T_{80}$ measured from $t=0$ for all devices.

tendency to crystalize produce the most stable EF-CBLs and longest-lived OPVs. For example, BP60 has the shortest operational lifetime among the EF-CBL devices with a thermally activated loss in FF due to BPhen crystallization that leads to junction shunts and increased recombination. This is in contrast to TP70 devices which were stable at temperatures as high as $130{ }^{\circ} \mathrm{C}$, leading to an operational lifetime of $T_{80}=2700 \mathrm{~h}$ and $E_{80}=5.9 \times 10^{8} \mathrm{~J} \mathrm{~m}^{-2}$ after continuous illumination. Under $5 \mathrm{~h}$ exposure to concentrated sunlight (100-suns), TP70 devices

Table 2. Power conversion efficiency (PCE) and device lifetime $\left(T_{80}\right)$, and $E_{80}$ for several organic photovoltaic cells.

\begin{tabular}{lccccc}
\hline Cell type & $\begin{array}{c}\text { PCE } \\
{[\%]}\end{array}$ & $\begin{array}{c}T_{80} \\
{[\mathrm{~h}]}\end{array}$ & $\begin{array}{c}E_{80} \\
{\left[\mathrm{~J} \mathrm{~m}^{-2}\right]}\end{array}$ & $\begin{array}{c}\text { Illumination } \\
\text { source* }\end{array}$ & Ref. \\
\hline Polymer & 2.7 & 12000 & $8.9 \times 10^{8}$ & S plasma & {$[47]$} \\
Small molecule & $6.6 \pm 0.6$ & 2700 & $5.9 \times 10^{8}$ & Xe arc & This work \\
Polymer & $5.5 \pm 0.15$ & 1200 & $2 \times 10^{8}$ & S plasma & {$[16]$} \\
Small molecule & 4.1 & 1600 & $1.9 \times 10^{8}$ & Halogen & {$[17]$} \\
(tandem) & & & & & \\
Small molecule & $3.2 \pm 0.05$ & 1700 & $1.5 \times 10^{8}$ & Xe arc & {$[18]$} \\
Small molecule & 2.1 & 1800 & $1.2 \times 10^{8}$ & Metal halide & {$[43]$} \\
Polymer & 5.1 & 250 & $4.2 \times 10^{7}$ & Metal halide & {$[44]$} \\
Polymer & 2.59 & 300 & $2.6 \times 10^{7}$ & $\mathrm{~N} / \mathrm{A}$ & {$[45]$} \\
Polymer & 3.1 & 200 & $2.1 \times 10^{7}$ & $\mathrm{~S}$ plasma & {$[46]$} \\
Polymer & 3.54 & 50 & $5.9 \times 10^{6}$ & $\mathrm{~N} / \mathrm{A}\left[50 \mathrm{~mW} \mathrm{~cm}{ }^{-2}\right]$ & {$[42]$} \\
Small molecule & 2.1 & 20 & $9.4 \times 10^{5}$ & Xe arc [75 mW cm $\left.{ }^{-2}\right]$ & {$[39]$} \\
Polymer & 1.4 & 1 & $4.6 \times 10^{4}$ & Xe arc & {$[41]$} \\
Polymer & 0.2 & $<1$ & 450 & $\mathrm{~N} / \mathrm{A}$ & {$[40]$} \\
\hline
\end{tabular}

$* N / A=$ information not available. experienced a $2 \%$ loss in $J_{\mathrm{SC}}$, which is comparable to that observed under continuous one sun intensity illumination of the same dose $(500 \mathrm{~h})$. However, during aging under sunlight, no performance loss was observed in a population of TP70 devices for $>100 \mathrm{~d}$.

Our results suggest that the morphological and photochemical stabilities of constituent layers are predictive of long-term device stability, and form a useful basis for the design and selection of OPV materials. The robustness of TP70 devices under extreme aging conditions including outdoor exposure, high temperature, and concentrated illumination is promising for the future of OPVs as a highly stable solar cell technology.

\section{Experimental Section}

The materials $\mathrm{Al}, \mathrm{MoO}_{3}, \mathrm{C}_{60}, \mathrm{C}_{70}$, DBP, BPhen, TPBi, 3TPYMB, and $\mathrm{BP} 4 \mathrm{mPy}$ were obtained from commercial sources. The chemical structural formulae for the exciton blocking materials and the electron conducting fullerenes are shown in Figure 1 and Figure 3. Devices were fabricated on prepatterned indium tin oxide (ITO)-coated glass substrates. Prior to use, the substrates were cleaned by sequential sonication in tergitol/deionised (DI) water solution, DI water, acetone, and isopropyl alcohol, followed by drying with ultrapure $\mathrm{N}_{2}$. Substrates were subsequently cleaned with a stream of supercooled $\mathrm{CO}_{2}$ gas for $1 \mathrm{~min}$, followed by a $10 \mathrm{~min}$ exposure to UV-ozone. ${ }^{[49]}$ Sapphire windows used for XRD measurements were similarly cleaned, omitting the UV-ozone treatment. The XRD diffraction patterns were obtained by illumination from a rotating anode, $\mathrm{Cu} \mathrm{K} \alpha$ source in the Bragg-Brentano configuration. The $\mathrm{KBr}$ windows for FTIR measurements were used without cleaning.

All layers were deposited by thermal evaporation in high vacuum $\left(<2 \times 10^{-7}\right.$ torr $)$ at rates between 0.2 and $1.6 \AA \mathrm{s}^{-1}$. Layer thicknesses and optical constants were measured using a variable angle spectroscopic ellipsometer. Device areas of $11.3 \mathrm{~mm}^{2}$ were defined by the intersection of the prepatterned ITO anode and a patterned Al cathode deposited through a shadow mask. Aging experiments were conducted without an optical aperture mask that confines illumination within the device active area so as to realistically simulate actual exposure conditions. Following fabrication, devices and thin films for XRD measurements were encapsulated by a cover glass in a glovebox filled with ultrahigh purity $\mathrm{N}_{2}\left(<1 \mathrm{ppm} \mathrm{O}_{2}\right.$ and $\left.\mathrm{H}_{2} \mathrm{O}\right)$ and sealed to the substrate with a UV-curable epoxy bead applied around its periphery. The packages contained a $\mathrm{BaO}_{x} / \mathrm{SrO}_{x}$ desiccant to remove residual $\mathrm{O}_{2}$ and $\mathrm{H}_{2} \mathrm{O}$ incorporated during packaging, or from small package leaks. The active layer used for absorbance measurements was deposited on quartz and packaged with a desiccant similar to the OPVs.

Substrates containing six OPV cells each were fabricated with the structure: $150 \mathrm{~nm} \quad \mathrm{ITO} / 10 \mathrm{~nm} \quad \mathrm{MoO}_{x} / 54 \mathrm{~nm}$ 1:8 DBP:C $C_{70} / 9 \mathrm{~nm} \mathrm{C} C_{70} / E F-C B L / 100 \mathrm{~nm}$ Al. The EF-CBL consisted of either $10 \mathrm{~nm}$ 1:1 BPhen: $\mathrm{C}_{60} / 5 \mathrm{~nm}$ BPhen (henceforth called BP60), $10 \mathrm{~nm}$ 1:1 3TPYMB: $\mathrm{C}_{60} / 5 \mathrm{~nm}$ 3TPYMB (3T60), $10 \mathrm{~nm}$ 1:1 TPBi: $\mathrm{C}_{70} / 3 \mathrm{~nm}$ TPBi (TP70), $10 \mathrm{~nm}$ 1:1 TPBi: $\mathrm{C}_{60} / 3 \mathrm{~nm}$ TPBi (TP60), or $10 \mathrm{~nm}$ 1:1 BP4mPy: $\mathrm{C}_{60} / 3 \mathrm{~nm}$ BP4mPy (BPPy60). Temperature dependent lifetime data were collected from devices fabricated in the same batch. All lifetime data shown are from a representative device on each substrate, where the device-to-device lifetime variation is included in the error bars along with the measurement error.

Fourier transform infrared spectra (Nicolet 6700) of $100 \mathrm{~nm}$ thick organic films on $\mathrm{KBr}$ were measured immediately following growth, while a companion film was aged under $1 \mathrm{~kW} \mathrm{~m}^{-2}$ xenon arc lamp illumination inside a glovebox filled with high purity $\mathrm{N}_{2}$ for 1 week prior to measurement. The FTIR spectrometer was purged with purified $\mathrm{N}_{2}$ for $>10$ min prior to measurement to remove ambient $\mathrm{H}_{2} \mathrm{O}$ and $\mathrm{CO}_{2}$, and spectra were corrected for atmospheric interference and to establish 
a signal baseline. Each spectrum from 400 to $4000 \mathrm{~cm}^{-1}$ consisted of averaging 32 scans with a resolution of $4 \mathrm{~cm}^{-1}$.

Differential scanning calorimetry (Perkin Elmer DSC-7) was performed on $0.1-2 \mathrm{mg}$ powder samples contained in a hermetically sealed Al pan. A heat-cool-heat cycle at $10{ }^{\circ} \mathrm{C} \mathrm{min}{ }^{-1}$ was performed from $25{ }^{\circ} \mathrm{C}$ to the subject material vacuum evaporation temperature to avoid decomposition.

Devices were aged under continuous illumination from a class AAA Xe arc lamp solar simulator at an intensity of $1 \mathrm{~kW} \mathrm{~m}^{-2}$. Packaged devices were mounted on printed circuit boards and connected to a current-voltage source meter through a relay multiplexer. During aging, each device was connected to a resistor to fix its current and voltage near the maximum power operating point. A resistive heater was placed on a $\mathrm{Cu}$ plate beneath each device to independently control temperature which was monitored using an integrated thermocouple. The current density versus voltage $(U-V)$ characteristics were measured twice per hour. One film prepared for XRD analysis was measured immediately following growth, while a separate sample from the same batch was aged in $\mathrm{N}_{2}$ under simulated solar illumination and then analyzed.

Devices for outdoor aging were fabricated and packaged as above, then mounted on a fixed-angle $\left(30^{\circ}\right)$ platform located at Sede Boqer $\left(30^{\circ} 51^{\prime} \mathrm{N}, 34^{\circ} 46^{\prime} \mathrm{E}\right)$ in the Negev Desert, Israel, where they remained under open-circuit conditions for $120 \mathrm{~d}$. Cell temperature was measured using a thermistor mounted directly on the device substrate, and solar irradiance was monitored with a calibrated Si photodetector. During periods when the solar irradiance was $>300 \mathrm{~W} \mathrm{~m}^{-2}$, fourth quadrant $J-V$ characteristics were measured twice per hour.

High light intensity (100 suns) device aging was also performed outdoors in Sede Boqer. Sunlight was collected, concentrated, and focused into a transmissive, $1 \mathrm{~mm}$ diameter quartz-core optical fiber coupled onto the OPV that operated at open circuit. ${ }^{[50,51]}$ Flux uniformity was achieved by placing a multimode, $3 \mathrm{~cm} \times 1 \mathrm{~cm} \times 1 \mathrm{~cm}$ quartz block between the cell and the fiber. Intensity was controlled with an iris, and measured using a spectrally blind calibrated pyranometer. ${ }^{[19]}$ The temperature of the illuminated area was estimated to be $\approx 100{ }^{\circ} \mathrm{C} .{ }^{[19,52]}$ Experiments were limited to clear-sky periods, $2.5 \mathrm{~h}$ around solar noon. The spectrum during this period was nearly invariant, and close to AM1.5G. ${ }^{[53]}$

\section{Acknowledgements}

The authors thank Vladimir Melnichak, Peter Su, and Shahar Dror for assistance in the design and operation of experimental setups. This work was partially financially supported by the United States Department of Energy SunShot Program under Awards DE-EE0006708 and DE-EE0005310 and Nanoflex Power Corp. Q.B. is grateful to the US-Israel Binational Science Foundation for providing a travel grant. E.A.K. thanks the Adelis Foundation. L.C. and G.Z. are thankful to the Ente Nazionale Energia e Ambiente and the Italian Ministry of Foreign Affairs for visitor post-doc fellowships to Ben Gurion University of the Negev.

Received: May 25, 2016

Revised: June 16, 2016

Published online: August 5, 2016

[1] K. Cnops, B. P. Rand, D. Cheyns, B. Verreet, M. A. Empl, P. Heremans, Nat. Commun. 2014, 5, 3406.

[2] Q. Zhang, B. Kan, F. Liu, G. Long, X. Wan, X. Chen, Y. Zuo, W. Ni, H. Zhang, M. Li, Z. Hu, F. Huang, Y. Cao, Z. Liang, M. Zhang, T. P. Russell, Y. Chen, Nat. Photonics 2014, 9, 35.

[3] A. N. Bartynski, C. Trinh, A. Panda, K. Bergemann, B. E. Lassiter, J. D. Zimmerman, S. R. Forrest, M. E. Thompson, Nano Lett. 2013, 13,3315
[4] X. Che, X. Xiao, J. D. Zimmerman, D. Fan, S. R. Forrest, Adv. Energy Mater. 2014, 4, 1400568

[5] S. B. Darling, F. You, RSC Adv. 2013, 3, 17633.

[6] F. C. Krebs, Stability and Degradation of Organic and Polymer Solar Cells, John Wiley \& Sons, Ltd, Chichester, UK 2012.

[7] S. A. Gevorgyan, M. V. Madsen, B. Roth, M. Corazza, M. Hösel, R. R. Søndergaard, M. Jørgensen, F. C. Krebs, Adv. Energy Mater. 2015, 6, 1501208.

[8] X. Xiao, K. J. Bergemann, J. D. Zimmerman, K. Lee, S. R. Forrest, Adv. Energy Mater. 2014, 4, 1301557.

[9] M. Y. Chan, C. S. Lee, S. L. Lai, M. K. Fung, F. L. Wong, H. Y. Sun, K. M. Lau, S. T. Lee, J. Appl. Phys. 2006, 100, 094506.

[10] Q. L. Song, C. M. Li, M. L. Wang, X. Y. Sun, X. Y. Hou, Appl. Phys. Lett. 2007, 90, 071109.

[11] S. W. Liu, C. C. Lee, W. C. Su, C. H. Yuan, Y. S. Shu, W. C. Chang, J. Y. Guo, C. F. Chiu, Y. Z. Li, T. H. Su, K. T. Chen, P. C. Chang, T. H. Yeh, Y. H. Liu, ACS Appl. Mater. Interfaces 2015, 7, 9262.

[12] F. C. Krebs, Stability and Degradation of Organic and Polymer Solar Cells, John Wiley \& Sons, West Sussex, UK, 2012.

[13] H. Cao, W. He, Y. Mao, X. Lin, K. Ishikawa, J. H. Dickerson, W. P. Hess, J. Power Sources 2014, 264, 168.

[14] M. O. Reese, S. A. Gevorgyan, M. Jørgensen, E. Bundgaard, S. R. Kurtz, D. S. Ginley, D. C. Olson, M. T. Lloyd, P. Morvillo, E. A. Katz, A. Elschner, O. Haillant, T. R. Currier, V. Shrotriya, M. Hermenau, M. Riede, K. R. Kirov, G. Trimmel, T. Rath, O. Inganäs, F. Zhang, M. Andersson, K. Tvingstedt, M. Lira-Cantu, D. Laird, C. McGuiness, S. Gowrisanker, M. Pannone, M. Xiao, J. Hauch, R. Steim, D. M. Delongchamp, R. Rösch, H. Hoppe, N. Espinosa, A. Urbina, G. Yaman-Uzunoglu, J. B. Bonekamp, A. J. J. M. van Breemen, C. Girotto, E. Voroshazi, F. C. Krebs, Sol. Energy Mater. Sol. Cells 2011, 95, 1253.

[15] O. Haillant, D. Dumbleton, A. Zielnik, Sol. Energy Mater. Sol. Cells 2011, 95, 1889.

[16] C. H. Peters, I. T. Sachs-Quintana, J. P. Kastrop, S. Beaupré, M. Leclerc, M. D. McGehee, Adv. Energy Mater. 2011, 1, 491.

[17] R. Franke, B. Maennig, A. Petrich, M. Pfeiffer, Sol. Energy Mater. Sol. Cells 2008, 92, 732.

[18] X. Tong, N. Wang, M. Slootsky, J. Yu, S. R. Forrest, Sol. Energy Mater. Sol. Cells 2013, 118, 116.

[19] I. Visoly-Fisher, A. Mescheloff, M. Gabay, C. Bounioux, L. Zeiri, M. Sansotera, A. E. Goryachev, A. Braun, Y. Galagan, E. A. Katz, Sol. Energy Mater. Sol. Cells 2015, 134, 99.

[20] T. Tromholt, E. A. Katz, B. Hirsch, A. Vossier, F. C. Krebs, Appl. Phys. Lett. 2010, 96, 073501.

[21] A. Manor, E. A. Katz, T. Tromholt, F. C. Krebs, Adv. Energy Mater. 2011, 1,836.

[22] J. Xue, B. P. Rand, S. Uchida, S. R. Forrest, Adv. Mater. 2005, 17, 66.

[23] K. Naito, A. Miura, J. Phys. Chem. 1993, 97, 6240.

[24] P. C. Eklund, Y. Wang, J. M. Holden, A. M. Rao, P. Zhou, Thin Solid Films 1995, 257, 185

[25] Q. Burlingame, X. Tong, J. Hankett, M. Slootsky, Z. Chen, S. R. Forrest, Energy Environ. Sci. 2015, 8, 1005.

[26] B. W. D'Andrade, S. R. Forrest, A. B. Chwang, Appl. Phys. Lett. 2003, 83, 3858

[27] S. Y. Chen, T. Y. Chu, J. F. Chen, C. Y. Su, C. H. Chen, Appl. Phys. Lett. 2006, 89, 2004.

[28] C. Bhugra, M. J. Pikal, J. Pharm. Sci. 2008, 97, 1329.

[29] J. D. Hoffman, J. Chem. Phys. 1958, 29, 1192.

[30] B. Song, Q. C. Burlingame, K. Lee, S. R. Forrest, Adv. Energy Mater. 2015, 5, 1401952.

[31] N. Wang, J. Yu, Y. Zang, J. Huang, Y. Jiang, Sol. Energy Mater. Sol. Cells 2010, 94, 263

[32] T. G. Fox, P. J. Flory, J. Appl. Phys. 1950, 21, 581.

[33] W. Chen, M. P. Nikiforov, S. B. Darling, Energy Environ. Sci. 2012, 5, 8045. 
[34] S. A. Hawks, G. Li, Y. Yang, R. A. Street, J. Appl. Phys. 2014, 116, 074503.

[35] N. C. Giebink, G. P. Wiederrecht, M. R. Wasielewski, S. R. Forrest, Phys. Rev. B 2010, 82, 155305.

[36] Y. Galagan, A. Mescheloff, S. C. Veenstra, R. Andriessen, E. A. Katz, Phys. Chem. Chem. Phys. 2015, 17, 3891.

[37] N. C. Giebink, B. W. D'Andrade, M. S. Weaver, J. J. Brown, S. R. Forrest, J. Appl. Phys. 2009, 105, 124514.

[38] N. C. Giebink, B. W. D'Andrade, M. S. Weaver, P. B. MacKenzie, J. J. Brown, M. E. Thompson, S. R. Forrest, J. Appl. Phys. 2008, 103, 044509.

[39] Q. L. Song, F. Y. Li, H. Yang, H. R. Wu, X. Z. Wang, W. Zhou, J. M. Zhao, X. M. Ding, C. H. Huang, X. Y. Hou, Chem. Phys. Lett. 2005, 416, 42

[40] F. C. Krebs, J. E. Carlé, N. Cruys-Bagger, M. Andersen, M. R. Lilliedal, M. A. Hammond, S. Hvidt, Sol. Energy Mater. Sol. Cells 2005, 86, 499.

[41] K. Kawano, R. Pacios, D. Poplavskyy, J. Nelson, D. D. C. Bradley, J. R. Durrant, Sol. Energy Mater. Sol. Cells 2006, 90, 3520.

[42] D. Gao, M. G. Helander, Z. Bin Wang, D. P. Puzzo, M. T. Greiner, Z. H. Lu, Adv. Mater. 2010, 22, 5404.

[43] G. Teran-Escobar, D. M. Tanenbaum, E. Voroshazi, M. Hermenau, K. Norrman, M. T. Lloyd, Y. Galagan, B. Zimmermann, M. Hösel, H. F. Dam, M. Jørgensen, S. Gevorgyan, S. Kudret, W. Maes, L. Lutsen, D. Vanderzande, U. Würfel, R. Andriessen, R. Rösch,
H. Hoppe, A. Rivaton, G. Y. Uzunoğlu, D. Germack, B. Andreasen, M. V Madsen, E. Bundgaard, F. C. Krebs, M. Lira-Cantu, Phys. Chem. Chem. Phys. 2012, 14, 11824.

[44] R. Roesch, K. R. Eberhardt, S. Engmann, G. Gobsch, H. Hoppe, Sol. Energy Mater. Sol. Cells 2013, 117, 59.

[45] A. Karpinski, S. Berson, H. Terrisse, M. Mancini-Le Granvalet, S. Guillerez, L. Brohan, M. Richard-Plouet, Sol. Energy Mater. Sol. Cells 2013, 116, 27.

[46] B. Zimmermann, U. Würfel, M. Niggemann, Sol. Energy Mater. Sol. Cells 2009, 93, 491.

[47] S. B. Sapkota, A. Spies, B. Zimmermann, I. Dürr, U. Würfel, Sol. Energy Mater. Sol. Cells 2014, 130, 144.

[48] D. C. Jordan, S. R. Kurtz, Prog. Photovoltaics Res. Appl. 2013, $21,12$.

[49] N. Wang, J. D. Zimmerman, X. Tong, X. Xiao, J. Yu, S. R. Forrest, Appl. Phys. Lett. 2012, 101, 133901.

[50] J. M. Gordon, E. A. Katz, D. Feuermann, M. Huleihil, Appl. Phys. Lett. 2004, 84, 3642.

[51] E. A. Katz, J. M. Gordon, W. Tassew, D. Feuermann, J. Appl. Phys. 2006, 100, 044514.

[52] A. Royne, C. J. Dey, D. R. Mills, Sol. Energy Mater. Sol. Cells 2005, 86,451

[53] E. A. Katz, D. Faiman, S. M. Tuladhar, J. M. Kroon, M. M. Wienk, T. Fromherz, F. Padinger, C. J. Brabec, N. S. Sariciftci, J. Appl. Phys. 2001, 90, 5343 . 